\title{
Fc $\gamma$ receptor IIA genotype and susceptibility to $P$. aeruginosa infection in patients with cystic fibrosis
}

\author{
Virginia De Rose ${ }^{*}, 1$, Carlo Arduino ${ }^{2}$, Nazario Cappello ${ }^{3}$, Rita Piana ${ }^{2}$, Paola Salmin ${ }^{2}$, \\ Marco Bardessono ${ }^{1}$, Manuela Goia ${ }^{1}$, Rita Padoan ${ }^{4,5}$, Elisabetta Bignamini ${ }^{6}$, \\ Diana Costantini ${ }^{4}$, Giovanna Pizzamiglio ${ }^{4}$, Veronica Bennato ${ }^{4}$, Carla Colombo ${ }^{4}$, \\ AnnaMaria Giunta ${ }^{7}$ and Alberto Piazza ${ }^{3}$
}

\begin{abstract}
${ }^{1}$ Respiratory Disease Division, Department of Clinical and Biological Sciences, University of Turin, Turin, Italy;
${ }^{2}$ Division of Genetics, San Giovanni Battista Hospital, Turin, Italy; ${ }^{3}$ Department of Genetics, Biology and Biochemistry, University of Turin, Turin, Italy; ${ }^{4}$ Cystic Fibrosis Centre, Istituti Clinici di Perfezionamento, University of Milan, Milan, Italy; ${ }^{5}$ Cystic Fibrosis Centre, Children's Hospital, Brescia; ${ }^{6}$ Cystic Fibrosis Centre, OIRM Sant'Anna Hospital, Turin, Italy; ${ }^{7}$ Institute of Paediatrics, University of Milan, Milan, Italy
\end{abstract}

It has been suggested that genes other than CFTR could modulate the severity of lung disease in cystic fibrosis (CF). Neutrophil Fc $\gamma$ receptor II (Fc $\gamma R$ II) is involved in host defense against microorganisms and in inflammatory response. We evaluated the association between genetic variability of this gene and both airway infection with Pseudomonas aeruginosa and severity of lung disease in patients with CF. We studied 167 Italian unrelated patients with CF and 50 control subjects. The distribution of FCyRIIA genotypes in CF patients was compared with that in control subjects and the different genotypes were related with the presence or absence of $P$. aeruginosa infection and markers of disease severity in CF patients. The distribution of FcyRIIA genotypes was not significantly different between CF patients and controls. We observed that in CF patients with the same CFTR genotype ( $\Delta F 508 / \Delta F 508)$, those carrying the $R$ allele of Fc $\gamma$ RIIA had an increased risk of acquiring chronic $P$. aeruginosa infection $(P=0.042$, R.R.: 4.38; $95 \% \mathrm{Cl}$ : $1.17 \div 22.4$ ). Moreover, the frequency of $R / R$ genotype in patients with chronic $P$. aeruginosa infection seems to be higher than that of control subjects and patients without chronic infection. The observation that CF patients carrying the $\mathrm{R}$ allele of $\mathrm{F}(\gamma \mathrm{RIIA}$ are at higher risk of acquiring chronic $P$. aeruginosa infection suggests that the FcyRII loci genetic variation is contributing to this infection susceptibility.

European Journal of Human Genetics (2005) 13, 96-101. doi:10.1038/sj.ejhg.5201285

Published online 15 September 2004

Keywords: cystic fibrosis; Fc $\gamma$ receptor II; P. aeruginosa; infection

Introduction

Cystic fibrosis (CF), the most common genetic disease in the white population, results from mutations in a single gene encoding for a 1480 residue transmembrane glyco-

*Correspondence: Dr V De Rose, Clinica di Malattie dell'Apparato Respiratorio, Dipartimento di Scienze Cliniche e Biologiche, Università di Torino, Ospedale S.Luigi Gonzaga, Regione Gonzole, 10, 10043 Orbassano, Torino, Italy. Tel: + 390119026 416; Fax: + 39011 9038674; E-mail: virginia.derose@unito.it

Received 3 July 2004; revised 22 July 2004; accepted 23 July 2004 protein, the CF transmembrane conductance regulator (CFTR), that regulates cAMP-mediated chloride conductance at the apical surface of secretory epithelia. ${ }^{1,2} \mathrm{CF}$ is characterized, in the classic form, by male infertility, pancreatic insufficiency and progressive obstructive lung disease. Lung disease accounts for most of the morbidity and mortality in patients with CF. Chronic airway infection with a specific flora, particularly Pseudomonas aeruginosa, and a marked and persistent inflammatory response in the airways are mainly responsible for progressive lung 
damage. ${ }^{1-3}$ There is, however, a remarkable heterogeneity in disease severity among patients with CF; whereas CFTR genotype is closely correlated with pancreatic status, the course of lung disease often differs considerably among patients, even in those carrying the same CFTR mutations, including siblings. ${ }^{4,5}$ Recent studies indeed indicate that, besides environmental factors, genes other than CFTR could modulate the severity of lung disease. ${ }^{6-10}$

Receptors for the $\mathrm{Fc}$ region of $\operatorname{IgG}(\mathrm{Fc} \gamma \mathrm{R})$ mediate multiple cell type specific functions including phagocytosis, release of inflammatory mediators, and clearance of immune complexes. Three major classes of $F c \gamma R$ exist in humans: Fc $\gamma$ RI, Fc $\gamma$ RII and $\mathrm{Fc} \gamma$ RIII. Human $\mathrm{Fc} \gamma \mathrm{R}$ genes have been mapped to Chromosome 1q21 (Fc $\gamma \mathrm{RI})$ and Chromosome 1q23-24 (Fc $\gamma$ RII-III). ${ }^{11,12}$ Fc $\gamma$ RII, constitutively expressed on neutrophils, is a low affinity receptor that interact only with complexed aggregated IgG and fulfils an important role in neutrophil defence against invading microorganisms. ${ }^{13}$ This receptor exhibits genetically determined structural and functional polymorphisms. A polymorphism of the gene for Fc $\gamma$ RIIa has been reported, in which a single-nucleotide change results in either arginine (R) or histidine $(\mathrm{H})$ at amino acid 131 of the mature protein. ${ }^{14-16}$ This change affects the ability of the receptor to bind certain IgG subclasses. In particular, only Fc $\gamma$ RIIA-H binds human IgG2 effectively. Conversely, Fc $\gamma$ RIIA-R binds murine IgG1, but Fc $\gamma$ RIIA-H does so poorly. ${ }^{16,17}$ The Fc $\gamma$ RIIA-H/R genotype has been associated to the risk of infection by encapsulated organisms. ${ }^{18,19}$ In studies using IgG2-opsonized encapsulated bacteria, phagocytosis by Fc $\gamma$ RIIA-HH PMN was significantly higher than in Fc $\gamma$ RIIA-RR PMN, which poorly ingested IgG2 opsonized bacteria. ${ }^{19-20}$ Fc $\gamma$ RII has also been shown to play a role in the pathophysiology of autoimmune diseases and polymorphisms within this gene have been reported to be associated with the risk or severity of autoimmune disorders. ${ }^{13,21-24}$

In this study, we evaluated whether there was an association between the different allotypes of Fc $\gamma$ RIIA and both airway infection with $P$. aeruginosa and severity of lung disease in patients with CF.

\section{Materials and methods \\ Sample}

In total, 167 patients with CF (88 males and 79 females) $7-54$ years of age (mean \pm SD:24.6 \pm 8.9 ) were studied. All were from Italy and unrelated. CF patients attended two CF Centres, in Turin and in Milan, Italy. The diagnosis of CF was based on a typical clinical profile with a positive sweat test and/or identification of mutations in both alleles of the CFTR gene. Control subjects were 50 unrelated Italian healthy subjects (26 males and 24 females, mean age: $34.2 \pm 9.5)$.

\section{Clinical assessment}

CF patients were seen on a regularly monthly basis at the two CF Centres. Clinical data recorded at the time of recruitment included age, sex, age at diagnosis, the presence or absence of pancreatic insufficiency, the presence or absence of chronic infection with $P$. aeruginosa, age at infection with $P$. aeruginosa, lung function parameters $\left(\mathrm{FEV}_{1}, \mathrm{FVC}\right)$.

Chronic infection was defined as persistent growth of bacteria for 6 months or more, continuously. ${ }^{25}$ Pulmonary function tests for $\mathrm{FEV}_{1}$ and FVC were performed using a computer-assisted spirometer (MasterLab; Jaeger, Wurzburg, Germany) and results were expressed as percentage of predicted values. ${ }^{26}$ The best values for $\mathrm{FVC}$ and $\mathrm{FEV}_{1}$ measured at clinical stability over the previous 6 months were used.

Of the 167 patients, 69 were homozygous for the $\Delta \mathrm{F} 508$ mutation; 61 were heterozygous for the $\Delta \mathrm{F} 508$ mutation, with the other CF mutation being identified in 40 patients; 37 patients carried two non- $\Delta$ F508 mutations.

The study conformed to the declaration of Helsinky and all subjects provided written informed consent.

\section{DNA extraction and analysis}

Genomic DNA was isolated from peripheral blood samples by conventional methods for the purpose of molecular analysis of CFTR. A sample of whole blood was drawn from each patient and stored at $-20^{\circ} \mathrm{C}$ until DNA was extracted using a standard method. The mutations most common in Italy were identified by oligonucleotide ligation assay (CF-OLA, Perkin-Elmer, Monza, Italy).

Screening for unknown mutations was carried out in all patients using Denaturant Gradient Gel Electrophoresis (DGGE) of all 27 exons as described by Fanen et $\mathrm{al}^{27}$ and samples presenting band shifts were directly sequenced (ABI PRISM 377, Perkin-Elmer).

Polymorphism analysis for the Fc $\gamma$ RIIA gene was performed according to previously reported assays. ${ }^{13,28,29}$

\section{Statistical analysis \\ Data were expressed as the median (range) for age at diagnosis and age at infection with $P$. aeruginosa and were compared using the unpaired Mann-Whitney $U$-test, because these variables were not normally distributed. All other continuous variables were expressed as mean $\pm \mathrm{SD}$ and were compared using the Student's $t$-test, while proportions were compared by means of $\chi^{2}$-statistics with the Yates correction, where applicable. The $95 \%$ confidence interval $(95 \% \mathrm{CI})$ was reported where appropriate. A two- sided $P$-value $<0.05$ was considered to be statistically significant. Multivariate analysis by the stepwise logistic regression and by the log-linear models was used to adjust for some potentially confounding factors (age, sex, the presence or absence of pancreatic insufficiency, pulmonary function values) and to estimate possible interactions}


between these factors. Univariate and multivariate analyses were performed by BMDP Statistical Software (release 7, 1992; University of California).

\section{Results}

In all, 167 patients with $\mathrm{CF}$ were studied. The distribution of the Fc $\gamma$ RIIA genotypes $H / H, H / R$ and $R / R$ is reported in Table 1 . The frequencies for the Fc $\gamma$ RIIA-H allele (0.58) and for the Fc $\gamma$ RIIA-R allele (0.42) were not significantly different from those in healthy control subjects ( 0.64 and 0.36 , respectively) and the distribution of the genotypes agrees with the Hardy-Weinberg equilibrium.

The clinical characteristics of the CF patients according to their Fc $\gamma$ RIIA genotype (absence/presence of the R allele) are reported in Table 2. Overall, 35 out of 53 patients with the $\mathrm{H} / \mathrm{H}$ genotype $(66 \%)$ and 74 out of 114 patients with $\mathrm{H} /$ $\mathrm{R}$ or R/R genotype (64.9\%) were infected with $P$. aeruginosa, the difference between the two groups being not statistically significant. No significant differences were observed either in age at diagnosis, age at onset of Pseudomonas infection, or lung function between patients with the $\mathrm{H} / \mathrm{H}$ genotype and those carrying at least one $\mathrm{R}$ allele.

To avoid any phenotypical heterogeneity resulting from allelic heterogeneity in the CFTR gene, we then analysed the association of the different Fc $\gamma$ RIIA genotypes and markers of disease severity in a subgroup of patients with the same CFTR genotype, that is, patients homozygous for the $\Delta \mathrm{F} 508$ mutation $(n=69)$. The frequency of $P$. aeruginosa infection was higher in patients with the R/R genotype of Fc $\gamma$ RIIA gene (90\%) as compared with patients with the

Table 1 Frequencies of Fc $\gamma$ RIIA genotypes in unrelated CF patients and healthy controls

\begin{tabular}{|c|c|c|c|c|}
\hline \multirow{2}{*}{$\begin{array}{l}\text { Fc } \gamma \text { RIIA } \\
\text { genotype }\end{array}$} & \multicolumn{2}{|c|}{ CF patients $(n=167)$} & \multicolumn{2}{|c|}{ Healthy controls $(n=50)$} \\
\hline & Number & $\%$ & Number & $\%$ \\
\hline $\begin{array}{l}\mathrm{H} / \mathrm{H} \\
\mathrm{H} / \mathrm{R} \\
\mathrm{R} / \mathrm{R}\end{array}$ & $\begin{array}{l}53 \\
88 \\
26\end{array}$ & $\begin{array}{l}31.7 \\
52.7 \\
15.6\end{array}$ & $\begin{array}{r}17 \\
30 \\
3\end{array}$ & $\begin{array}{r}34 \\
60 \\
6\end{array}$ \\
\hline
\end{tabular}

$\mathrm{H} / \mathrm{H}$ genotype (63.6\%), although univariate analysis did not show significant difference between the two groups, possibly for the relatively small sample size. There was also a trend toward a younger age at diagnosis and a younger age at onset of chronic $P$. aeruginosa infection and lower values of $\mathrm{FVC}$ and $\mathrm{FEV}_{1}$ in patients carrying the $\mathrm{R} / \mathrm{R}$ genotype as compared with those carrying the $\mathrm{H} / \mathrm{H}$ genotype, but also in this case the difference did not reach statistical significance (Table 3 ).

When infection was analysed by making it dependent on age, sex, presence or absence of pancreatic insufficiency, age at diagnosis, $\mathrm{FEV}_{1}$ and $\mathrm{FVC}$ in a multivariate logistic regression model, Fc $\gamma$ RIIA $H / R$ and $R / R$ genotypes were found associated with a fourfold higher risk of being affected by chronic $P$. aeruginosa infection $(P=0.042$, relative risk: 4.38 ; $95 \% \mathrm{CI}: 1.17 \div 22.4$ ). As expected, FVC and $\mathrm{FEV}_{1}$ values were also associated with $P$. aeruginosa infection (Table 4).

To further exclude a potential bias due to the presence in our sample of patients 7-12 years old, which is a critical age for the acquisition of chronic $P$. aeruginosa infection, multivariate analysis was also carried out separately in patients older than 11 years and older than 12 years. Both analyses did not affect the results (data not shown but available on request): the overall conclusion regarding the

Table 2 Clinical data of CF patients according to their Fc $\gamma$ RIIA genotype

\begin{tabular}{lcc}
\hline & $H H$ & $H R+R R$ \\
\hline Patients no. & 53 & 114 \\
Age, years & $23.99 \pm 7.71$ & $24.83 \pm 9.52$ \\
Sex (M/F) & $33 / 20$ & $55 / 59$ \\
Age at diagnosis & $3(0-40)$ & $4(0-52)$ \\
P. aeruginosa infected & $35(66.0 \%)$ & $74(64.9 \%)$ \\
Age at onset of Ps. infection & $12(2-26)$ & $12(0.25-52)$ \\
FVC\% predicted & $81.30 \pm 16.80$ & $74.98 \pm 21.90$ \\
FEV1\% predicted & $67.51 \pm 20.43$ & $66.61 \pm 23.83$ \\
Pancreatic insuff. no. (\%) & $37(69.8 \%)$ & $74(64.9 \%)$ \\
$\Delta$ F508/ F508 no. (\%) & $22(41.5 \%)$ & $47(41.2 \%)$ \\
$\Delta$ F508/other no. (\%) & $19(35.8 \%)$ & $42(36.8 \%)$ \\
Other/other no. (\%) & $12(22.6 \%)$ & $25(21.9 \%)$ \\
\hline
\end{tabular}

Table 3 Clinical data of homozygous $\Delta \mathrm{F} 508 \mathrm{CF}$ patients according to their Fc $\gamma \mathrm{RIIA}$ genotype

\begin{tabular}{|c|c|c|c|c|}
\hline & $H H$ & $H R$ & $R R$ & $H R+R R$ \\
\hline
\end{tabular}


relationship between Fc $\gamma$ RIIA genotypes and susceptibility to chronic $P$. aeruginosa infection still holds.

Both in the whole sample and in the subgroup of patients homozygous for the $\Delta \mathrm{F} 508$ mutation the $\mathrm{R} / \mathrm{R}$ genotype was more frequent in patients with $P$. aeruginosa infection (18.3 and $18.7 \%$, respectively) as compared with control subjects $(6 \%)$ or with patients without infection (10.3\% for the overall population and $4.8 \%$ for the $\Delta \mathrm{F} 508$ homozygous patients) (Table 5). Although this difference was not statistically significant, this finding is consistent with the observation that there is an association between Fc $\gamma$ RIIA polymorphism and chronic $P$. aeruginosa infection in CF patients, and supports the hypothesis that the presence of the $\mathrm{R}$ allele or the absence of the $\mathrm{H}$ allele may confer susceptibility to $P$. aeruginosa infection.

\section{Discussion}

Progressive lung disease is the major cause of morbidity and mortality in CF. A vicious circle of airway infection and inflammation occurs early in the course of the disease, leading to progressive lung damage and, eventually, respiratory failure. ${ }^{1-3}$ However, patients with CF show a remarkable variability in pulmonary involvement which is largely unexplained; in fact, whereas CFTR genotype is closely correlated with pancreatic status, the course of lung disease often differs markedly between patients, even in those who carry the same CFTR mutations, who share a similar environment and who attend the same CF centre. ${ }^{4,5}$ Thus, it has been suggested that genes other

Table 4 Stepwise logistic regression analysis to identify factors possibly affecting the risk of chronic $P$. aeruginosa infection

\begin{tabular}{lccc}
\hline Variable & $\begin{array}{c}\text { Relative risk } \\
(\text { R.R.) }\end{array}$ & $\begin{array}{c}95 \% \mathrm{Cl} \text { of } \\
\text { R.R. }\end{array}$ & $P$ \\
\hline FC $\gamma$ RIIA genotypes: & 4.38 & $1.17 \div 22.4$ & 0.042 \\
H/H vs H/R+R/R & & & \\
FVC & 1.13 & $1.00 \div 1.27$ & 0.002 \\
FEV $_{1}$ & 1.14 & $1.02 \div 1.25$ & 0.004 \\
\hline
\end{tabular}

than CFTR could modulate the severity of the bronchopulmonary disease. ${ }^{6-8}$

In this study, we have examined the effect of genetic variability by a gene, Fc $\gamma$ RIIA, involved in host defence and inflammatory response on chronic $P$. aeruginosa infection and lung disease severity in patients with CF. Whereas in the overall population studied, an association between the different genotypes of this gene and both chronic Pseudomonas infection and disease severity was not evident, in a subgroup of CF patients with the same CFTR genotype $(\Delta \mathrm{F} 508 / \Delta \mathrm{F} 508)$ we found that patients carrying the $\mathrm{R}$ allele of $\mathrm{Fc} \gamma \mathrm{RIIA}$ had an increased risk of acquiring chronic $P$. aeruginosa infection as compared with patients not carrying the $\mathrm{R}$ allele. We also observed that there was a trend toward an increased frequency of $\mathrm{R} / \mathrm{R}$ genotype in patients with chronic $P$. aeruginosa infection compared with control subjects and patients without chronic infection.

Several factors such as age, sex, and the severity of the disease may affect chronic $P$. aeruginosa acquisition in CF. This may account for the lack of statistical significance between Fc $\gamma$ RIIA genotypes by using univariate analysis. After correction for these potential confounding factors by multivariate logistic regression model, we observed in fact that beside Fc $\gamma$ RIIA genotype, other parameters, that is, FVC and $\mathrm{FEV}_{1}$ were affecting the risk of acquiring $P$. aeruginosa infection. The association of $\mathrm{FVC}$ and $\mathrm{FEV}_{1}$ values with $P$. aeruginosa infection is not surprising, as epidemiological studies indicate that chronic infection by $P$. aeruginosa is associated to significant increase in the rate of decline of pulmonary function. The observation that the frequency of $\mathrm{R} / \mathrm{R}$ genotype is increased in patients with $P$. aeruginosa infection as compared with control patients and patients without infection supports the hypothesis that the presence of the R allele of Fc $\gamma$ RIIA or the absence of the $\mathrm{H}$ allele may confer susceptibility to $P$. aeruginosa infection.

Although previous reports ${ }^{8}$ did not find an association between CFTR genotype and risk of acquiring $P$. aeruginosa infection, the lack of association between Fc $\gamma$ RIIA genotype and chronic infection observed in the whole sample in this study emphasizes the importance of selecting a homo-

Table 5 Frequencies of Fc $\gamma$ RIIA genotypes in CF patients with and without chronic $P$. aeruginosa infection and in healthy controls

\begin{tabular}{|c|c|c|c|c|}
\hline \multirow[t]{2}{*}{ Group } & \multirow[t]{2}{*}{ Number } & \multicolumn{3}{|c|}{ FcyRIIA genotype, $n(\%)$} \\
\hline & & $H / H$ & $H / R$ & $R / R$ \\
\hline Healthy controls & 50 & $17 / 50(34 \%)$ & $30 / 50(60 \%)$ & $3 / 50(6 \%)$ \\
\hline CF patients (overall population) & 167 & $53(31.6 \%)$ & $88(52.4 \%)$ & $26(15.5 \%)$ \\
\hline With $P$. aeruginosa infection & 109 & $35(32.1 \%)$ & $54(49.5 \%)$ & $20(18.3 \%)$ \\
\hline Without $P$. aeruginosa infection & 58 & $18(31.0 \%)$ & $34(58.6 \%)$ & $6(10.3 \%)$ \\
\hline CF patients homozygous $\Delta \mathrm{F} 508$ & 69 & $22(31.9 \%)$ & $37(53.6 \%)$ & $10(14.5 \%)$ \\
\hline With $P$. aeruginosa infection & 48 & $14(29.2 \%)$ & $25(52.1 \%)$ & $9(18.7 \%)$ \\
\hline Without $P$. aeruginosa infection & 21 & $8(38.1 \%)$ & $12(57.1 \%)$ & $1(4.8 \%)$ \\
\hline
\end{tabular}


geneous group of CF patients, that is, with an identical CFTR genotype, when studying modifier genes for CF disease. In fact, patients with mild CFTR mutations such as class IV and V mutations have mild disease and therefore could be less susceptible to Pseudomonas. Furthermore, even severe CFTR mutations associated with severe form of the disease could differently affect $P$. aeruginosa susceptibility. It has been suggested that CFTR is involved in binding and internalization of $P$. aeruginosa by epithelial cells $^{30}$; class III mutant CFTR, that is present on the apical membrane of epithelial cells could maintain this function and patients with this mutation could therefore be less susceptible to $P$. aeruginosa infection.

As a whole, our results suggest that, although the presence of the $\mathrm{R}$ allele of Fc $\gamma$ RIIA is related to a higher risk of acquiring $P$. aeruginosa infection, other factors may indeed contribute to this increased risk.

Chronic $P$. aeruginosa lung infection is the leading cause of death in patients with CF. It is primarily this infection that leads to a heightened and persistent inflammatory response and progressive tissue destruction in the CF lung. Chronic infection by $P$. aeruginosa, in $\mathrm{CF}$, is associated with high serum levels of IgG2 anti-Pseudomonas antibodies and immune complexes containing IgG2 antibodies, which are correlated with poor lung function and poor clinical condition. $^{31-33}$ LPS, a prominent cell wall component common to Gram-negative bacilli, is a key antigen for the humoral recognition and clearance of $P$. aeruginosa; IgG subclasses response to Pseudomonas LPS is restricted largely to IgG2.

Expression of $\mathrm{Fc} \gamma$ receptors on the surface of phagocytic cells conveys to the cells the ability to recognize, bind and internalize IgG-opsonized particulate antigens and immune complexes. Fc $\gamma$ RIIA is the only allotype of $\mathrm{Fc} \gamma$ receptor that efficiently recognizes IgG2, an IgG isoform that plays an important role in the defense against infection with bacteria such as $S$. pneumoniae, H. influenzae, $N$. meningitidis, and $P$. aeruginosa. ${ }^{18,34-35} \mathrm{Fc} \gamma$ RIIA exists in two allelic forms that differ in the amino acid at position 131 (arginine R131/histidine H131) in the second immunoglobulin-like domain. ${ }^{14-16}$ Interestingly, polymorphisms at this site influence the binding of IgG2 to Fc $\gamma$ RIIA, with individuals homozygous for R/R unable to bind IgG2 opsonized bacteria efficiently; both heterozygous Fc $\gamma$ RIIA $\mathrm{H} / \mathrm{R}$ and homozygous R/R PMN proved to be significantly less efficient in phagocytosis and intracellular activation of oxidative burst than did homozygous H/H PMN. ${ }^{17,19,20}$ In $\mathrm{CF}$, where bacterial colonization of the lung by $P$. aeruginosa is associated with high serum levels of IgG2 anti-P. aeruginosa antibodies and immune complexes containing IgG2 anti-Pseudomonas antibodies, the potential for the IgG2 antibodies to act as poor opsonins and affect the clearance of these microorganisms may vary in accord with $\mathrm{H} / \mathrm{R}$ genotype. PMN from patients carrying the $\mathrm{R}$ allele of Fc $\gamma$ RIIA would be less effective in binding and therefore clearing organisms opsonized by serum with elevated IgG2, and this would explain the increased susceptibility of these patients to chronic Pseudomonas infection.

Consistent with our findings, previous studies have shown an increased susceptibility to bacterial infections by encapsulated bacteria in patients with the R/R genotype of Fc $\gamma$ RIIA $^{18,35}$ and it has been reported that the frequency of both heterozygous Fc $\gamma$ RIIA H/R and homozygous R/R was higher in patients with recurrent bacterial respiratory tract infections than in controls. ${ }^{18}$ However, the lack of difference in the frequency of Fc $\gamma$ RIIA genotypes in CF patients and control subjects observed in this study and the lack of association between these genotypes and other parameters of disease severity, as well as the contribution of other variables to the increased risk of acquiring $P$. aeruginosa infection, support the concept that the severity of pulmonary involvement in CF is controlled by multifactorial genetic mechanisms and suggest that other genetic factors may influence susceptibilities and outcomes in which $\mathrm{Fc} \gamma$ receptors play a role.

In conclusion, this study shows that CF patients carrying the $\mathrm{R}$ allele of $\mathrm{F} \gamma \mathrm{\gamma}$ RIIA are at higher risk of acquiring chronic $P$. aeruginosa infection, suggesting that the Fc $\gamma$ RII loci genetic variation is contributing, among other possible genetic factors, to this infection susceptibility.

\section{References}

1 Davis PB, Drumm M, Konstan MW: Cystic fibrosis: state of the art. Am J Respir Crit Care Med 1996; 154: 1229-1256.

2 Welsh MJ, Tsui L, Boat TF, Beaudet AL: Cystic fibrosis; In: Scriver CR, Beaudet AL, Sly WS, Valle D (eds) The metabolic and molecular bases of inherited disease. New York: McGraw-Hill, 1995, pp 3799-3876.

3 Konstan MW, Berger M: Infection and inflammation in the lung in cystic fibrosis; In: Davis PB (ed) Cystic fibrosis. Marcel Dekker: New York, 1993, pp 219-276.

4 Zielenski J, Tsui LC: Cystic fibrosis: genotypic and phenotypic variations. Аnnu Rev Genet 1995; 29: 777-807.

5 Kerem B, Kerem E: The molecular basis for disease variability in cystic fibrosis. Eur J Hum Genet 1996; 4: 65-73.

6 Hull J, Thomson AH: Contribution of genetic factors other than CFTR to disease severity in cystic fibrosis. Thorax 1998; 53: $1018-1021$.

7 Garred P, Pressler T, Madsen HO et al: Association of mannosebinding lectin gene heterogeneity with severity of lung disease and survival in cystic fibrosis. J Clin Invest 1999; 104: 431-437.

8 Aron Y, Polla BS, Bienvenu T, Dall'Ava J, Dusser D: HLA Class II polymorphism in cystic fibrosis. A possible modifier phenotype. Am J Respir Crit Care Med 1999; 159: 1464-1468.

9 Zielenski J, Corey M, Rozmahel R: Detection of a cystic fibrosis modifier locus for meconium ileus on human chromosome 19q13. Nat Genet 1999; 22: 128-129.

10 Rozmahel R, Wilschanski M, Matin A: Modulation of disease severity in cystic fibrosis transmembrane conductance regulator deficient mice by a secondary genetic factor. Nat Genet 1996; 12: 280-287.

11 De Wit TPM, Suijkerbuik RF, Capel PJA, van Kessel AG, Van de Winkel JGJ: Assignment of three human high-affinity $\mathrm{Fc} \gamma$ receptor genes to chromosome 1, band q21.1. Immunogenetics 1993; 38: $57-59$. 
12 Peltz GA, Grundy HO, Lebo RV, Yssel H, Barsh GS, Moore KW: Human Fc gamma RIII: cloning, expression, and identification of the chromosomal locus of two Fc receptors for IgG. Proc Natl Acad Sci USA 1986; 86: 1013-1017.

13 Van de Winkel JGJ, Capel JA: Human IgG Fc receptor heterogeneity: molecular aspects and clinical implications. Immunol Today 1993; 14: 215-221.

14 Clark MR, Clarkson SB, Ory PA, Stollman N, Goldstein IM: Molecular basis for a polymorphism involving Fc receptor II on human monocytes. J Immunol 1989; 143: 1731-1734.

15 Wamerdam PAM, Van de Winkel JGJ, Gosselin EJ, Capel PJA: Molecular basis for a polymorphism of human $\mathrm{Fc} \gamma$ receptor II (CD32). J Exp Med 1990; 172: 19-25.

16 Warmerdam PAM, Van de Winkel JGJ, Vlug A, Westerdaal NAC, Capel PJA: A single aminoacid in the second Ig-like domain of the human Fcy receptor II is critical for human IgG2 binding. J Immunol 1991; 147: 1338-1343.

17 Parren PWHI, Warmerdam PAM, Boeije LCM et al: On the interaction of IgG subclasses with the low affinity Fc $\gamma$ RIIa (CD32) on human monocytes, neutrophils, and platelets. Analysis of a functional polymorphism to human IgG2. J Clin Invest 1992; 90: 1537-1546.

18 Sanders LAM, Van de Winkel JGJ, Rijkers GT et al: Fc $\gamma$ receptor II a (CD32) heterogeneity in patients with recurrent bacterial respiratory tract infections. J Inf Dis 1994; 170: 854-861.

19 Bredius RGM, de Vires CEE, Troelstra A et al: Phagocytosis of Staphylococcus aureus and Haemophilus influenzae type B opsonized with polyclonal human IgG1 and IgG2 antibodies. I Immunol 1993; 151: 1463-1472.

20 Salmon JE, Edberg JC, Brogle NL, Kimberly RP: Allelic polymorphisms of human $\mathrm{Fc} \gamma$ receptor IIA and $\mathrm{F} \gamma \gamma$ receptor IIIB. Independent mechanisms for differences in human phagocyte function. J Clin Invest 1992; 89: 1274-1281.

21 Salmon JE, Millard S, Schachter LA et al: Fc $\gamma$ RIIa alleles are heritable risk factors for lupus nephritis in African-Americans. J Clin Invest 1996; 97: 1348-1354.

22 Manger K, Repp R, Spriewald BM et al: Fc $\gamma$ receptor IIa polymorphism in Caucasian patients with systemic lupus erythematosus. Association with clinical symptoms. Arthritis Rheum 1998; 41: 1181-1189.

23 Edberg JC, Wainsten E, Wu J et al: Analysis of Fc $\gamma$ RII gene polymorphisms in Wegener's granulomatosis. Exp Clin Immunogenet 1997; 14: 183-195.

24 Michel M, Piette J-C, Roullet E et al: The R131 low-affinity allele of the Fc gamma RIIA receeptor is associated with systemic lupus erythematosus but not with other autoimmune diseases in French Caucasians. Am J Med 2000; 108: 580-583.

25 Doring G, Conway SP, Heijerman HG et al: Antibiotic therapy against Pseudomonas aeruginosa in cystic fibrosis: a European consensus. Eur Respir J 2000; 16: 749-767.

26 Quanjer PH, Tammeling GJ, Cotes JE, Pedersen OF, Peslin R, Yernault JC: Lung volumes and forced ventilatory flows. Report of a Working Party on Standardization of Lung Function Tests, European Community for Steel and Coal. Official Statement of the European Respiratory Society. Eur Respir J 1993; 6 (Suppl 16): $5-40$.

27 Fanen P, Ghanem N, Vidaud M et al: Molecular characterisation of cystic fibrosis: 16 novel mutations identified by analysis of the whole cystic fibrosis transmembrane conductance regulator (CFTR) coding regions and splice site junctions. Genomics 1992; 13: $770-776$

28 Jang XM, Arepally G, Poncz M, McKenzie SE: Rapid detection of the Fc gamma RIIA-H/R 131 ligand-binding polymorphism using an allele-specific restriction enzyme digestion (ASRED). J Immunol Methods 1996; 199: 55-59.

29 Hessner MJ, Curtis BR, Endean DJ, Aster RH: Determination of neutrophil antigen frequencies in five ethnic groups by polymerase chain reaction with sequence-specific primers. Transfusion 1996; 36: 895-899.

30 Pier GB, Grout M, Zaidi TS: Cystic fibrosis transmembrane conductance regulator is an epithelial cell receptor for clearance of Pseudomonas aeruginosa from the lung. Proc Natl Acad Sci USA 1997; 94: $12088-12093$.

31 Hoiby N: Pseudomonas aeruginosa infection in cystic fibrosis. Diagnostic and prognostic significance of Pseudomonas aeruginosa precipitins determination by means of crossed immunoelectrophoresis. A survey. Acta Pathol Microbiol Scand 1977; 262: 1-96.

32 Hodson ME, Beldon I, Batten JC: Circulating immune complexes in patients with cystic fibrosis in relation to clinical features. Clin Allergy 1985; 15: 363-370.

33 Koch C, Hoiby N: Pathogenesis of cystic fibrosis. Lancet 1993 341: $1065-1069$

34 Pressler T, Mansa B, Jensen T et al: Increased IgG2 and IgG3 concentration is associated with advanced Pseudomonas aeruginosa infection and poor pulmonary function in cystic fibrosis. Acta Paediatr Scand 1988; 77: 576-582.

35 Domingo P, Muniz-Diaz E, Baraldes MA et al: Associations between Fc gamma receptor IIA polymorphisms and the risk and prognosis of meningococcal disease. Am J Med 2002; 112: $19-25$. 